\title{
BENEFÍCIOS DA REVOLUÇÃO RUSSA
}

\author{
BENEFICIOS DE LA REVOLUCIÓN RUSA
}

\section{BENEFITS OF THE RUSSIAN REVOLUTION}

DOI: http://dx.doi.org/10.9771/gmed.v11i1.30690

\begin{abstract}
Nelson Kautzner Marques Junior ${ }^{1}$
Resumo: O objetivo da revisão foi de apresentar os benefícios da revolução russa referente ao direito trabalhista, na saúde e na educação, no esporte. Até o século XX na Rússia o trabalhador não tinha nenhum direito trabalhista, mas com a revolução russa o povo conquistou vários benefícios -8 horas de serviço, férias remuneradas etc. A saúde e a educação passaram a ser gratuitos na Rússia revolucionária. Em 1917 Kotov elaborou uma periodização e depois foram feitas outras pesquisas sobre esse tema onde resultaram em outros modelos. Em conclusão, o socialismo é o meio da sociedade se tornar mais igualitária e com melhor qualidade de vida.
\end{abstract}

Palavras-chave: Revolução. Trabalho. Esporte. Educação. Saúde.

Resumen: El objetivo de la revisión fue presentar los beneficios de la revolución rusa referente al derecho laboral, la salud y la educación, en el deporte. Hasta el siglo XX en Rusia el trabajador no tenía ningún derecho laboral, pero con la revolución rusa el pueblo conquistó varios beneficios - 8 horas de servicio, vacaciones remuneradas, etc. La salud y la educación pasaron a ser gratuitas en Rusia revolucionaria. En 1917 Kotov elaboró una periodización y luego se realizaron otras investigaciones sobre ese tema donde resultaron en otros modelos. En conclusión, el socialismo es el medio de que la sociedad se vuelva más igualitaria y con mejor calidad de vida.

Palabras clave: Revolución. Trabajo. Deporte. Educación. Salud.

Abstract: The purpose of the review was to present the benefits of the Russian revolution regarding labor law, health and education, sport. Until the twentieth century in Russia the worker had no labor law, but with the Russian revolution the people gained several benefits -8 hours of service, paid holidays, etc. Health and education became free in revolutionary Russia. In 1917 Kotov elaborated a periodization and after others researches practiced studies about this theme and elaborated others models. In conclusion, socialism is the means for society to become more egalitarian and with a better quality of life.

Keywords: Revolution. Job. Sport. Education. Health.

\section{Introdução}

A Rússia do século XIX era uma nação de capitalismo atrasado sob o comando do império do czar. O povo russo se concentrava no campo trabalhando para os nobres proprietários de terra através do serviço agrícola durante 14 a 15 horas sendo fornecido baixo salário (SANTOS; SANTOS; COSTA, 2014). Os camponeses eram proibidos de fazer greve, de organizar sindicatos e não tinham nenhum direito trabalhista.

No fim do século XIX e no início do século XX as principais cidades da Rússia como Moscou e São Petersburgo (foi até 1914) iniciaram uma significativa industrialização que atraiu os camponeses para essas cidades. Porém nas fábricas, a condição do serviço era muito difícil e o trabalho tinha mais de 10 
horas com baixo salário. Portanto, o czar gerava pobreza para a população. Isso se agravou em 1904 a 1905 durante a guerra da Manchúria entre Rússia e Japão (NOGUEIRA, 2013).

A guerra da Manchúria causou insatisfação do povo que se organizou politicamente em 1905 através dos sovietes ou conselhos (SANTOS, 2018). Os sovietes objetivavam defender os interesses políticos dos trabalhadores através de manifestações e eram constituídos por operários, por militares de baixa patente, por camponeses e por partidos políticos (BARTZ, 2008). Um dos partidos políticos que participavam dos sovietes era o Partido Operário Social Democrata Russo (POSDR, foi fundado em 1898) que seguia as ideias do socialismo de Marx e Engels e objetivava organizar o povo russo contra o czar. Esse partido político era constituído pela maioria dos bolcheviques e tendo Lênin como líder e pela minoria dos mencheviques. Lênin venceu uma eleição e se tornou líder do POSDR.

A partir de 1905 aconteceram diversas greves na Rússia organizada pelos sovietes reivindicando salários mais elevados, menor jornada de trabalho e outros. No dia 9 de janeiro de 1905, muitos manifestantes orientados pelos sovietes protestaram na frente do Palácio de Inverno do czar em São Petersburgo, mas a guarda imperial atirou e muitos morreram - é o "domingo sangrento" (ALBUQUERQUE, 2018). Porém, ainda aconteceram diversas manifestações e greves até dezembro de 1905, os principais líderes como Lênin, Trotski tiveram que se exilar para não serem presos.

No ano de 1914 a cidade de São Petersburgo passou a se chamar de Petrogrado e a Rússia entrou na $1^{\text {a }}$ Guerra Mundial (1 ${ }^{\text {a }}$ GM foi de 1914 a 1918). Já em 1915 o exército russo se encontrava em péssimas condições para o combate porque a comida para os soldados era insuficiente por causa da escassez de alimentos produzidos no campo e na cidade (GONZÁLEZ, 1986). A guerra aumentou a pobreza do povo e aconteceram diversas greves e manifestações. Em 23 de fevereiro de 1917 era Dia Internacional da Mulher, pelo calendário vigente dos países ocidentais era 8 de março de 1917, mas ocorreu greve com manifestação espontânea das mulheres operárias pelas ruas de Petrogrado tendo a palavra de ordem "pão, paz e terra" (SANTOS, 2018). As operárias pediam pão por causa da fome, a paz estava relacionada com a retirada da Rússia da $1^{a} \mathrm{GM}$ e a terra as manifestantes pediam a reforma agrária. Os soldados e policiais do czar tentaram conter a manifestação, mas não foi possível porque até o dia 27 de fevereiro de 1917 o número de manifestações aumentou, aderindo esse ato até as forças opressoras do czar (ALBUQUERQUE, 2018). No dia 27 de fevereiro de 1917 o czar abdicou o poder e foi formado um governo provisório com a liderança de Kerensky. A manifestação realizada pelas mulheres do dia 23 a 27 de fevereiro de 1917 contagiou todo o povo russo e não teve a participação de nenhum líder político porque eles estavam no exílio - Trotsky nos Estados Unidos e Lênin na Suíça (SECCO, 2017). O governo provisório logo recebeu desaprovação do povo porque ele não tirou a Rússia da $1^{\mathrm{a}}$ GM e a pobreza aumentava cada vez mais.

Como o governo provisório continuava enfraquecido e o povo permanecia em extrema pobreza, no mês de julho de 1917 aconteceram diversos protestos organizados pelos bolcheviques com o intuito de tirar o governo provisório (DOS SANTOS, 2017). Esses atos sucessivos nas ruas de Petrogrado foram denominados de Jornadas de Julho. Após as forças militares inibirem os protestos, alguns líderes 
foram presos, o caso de Trotsky, e outros retornaram para o exílio, Lênin fugiu para a Finlândia. Aproveitando esse tumulto, em 28 de agosto de 1917 em Petrogrado, o general Kornilov das forças armadas russas comandou um golpe de estado para tirar Kerensky do poder, mas essa iniciativa fracassou porque as forças armadas simpatizantes do governo provisório com ajuda dos sovietes evitaram essa ação (MATTOS, 2017).

No início de outubro de 1917 na cidade de Petrogrado os sovietes definiram que outubro era ideal para os trabalhadores assumirem o poder porque o governo provisório estava muito enfraquecido. Lênin estabeleceu nesse soviete que a palavra de ordem era "terra, pão e paz: todo o poder aos sovietes" (MACAMBIRA, 2017). No dia 25 de outubro de 1917 em Petrogrado, os sovietes estavam armados tendo o comando de Trotsky e tomaram o poder das principais regiões da cidade (correio, pontes, telégrafo, edifícios públicos etc) e até do palácio de inverno do czar. Após a queda do governo provisório e do czar, iniciou a implantação do comunismo na Rússia e os sovietes aplicaram a ditadura do proletariado, momento que a classe trabalhadora assumiu o poder e realizou uma divisão igualitária das riquezas dos mais abastados para o povo russo.

Então, o governo bolchevique realizou a reforma agrária, os operários assumiram o controle das fábricas, foi fornecido moradia e emprego para todos, foi estabelecida igualdade salarial entre homens e mulheres e outros (PIMENTA, 2012). As mulheres prostitutas na Rússia foram reconhecidas como profissão (MUSSI, 2017) e os direitos trabalhistas originaram e/ou foram difundidos pelo mundo por causa da revolução russa, onde o empregado passou a ter direito a aposentadoria (PIMENTA, 2017), foi instituído que o trabalhador necessita de férias remuneradas e a empresa precisa fornecer assistência à saúde ao empregado, as mulheres que deram luz tornou obrigatório à licença a maternidade, nas fábricas tornou obrigatório uso de equipamentos de segurança e outros (MARQUES JUNIOR, 2017). Também foi estabelecido ensino gratuito para todas as idades. Logo em 1917, tornou obrigatório nas escolas a atividade física e o esporte (CÓRDOBA; CONTRERAS, 2015). Por último, o povo russo passou a ter acesso a médico gratuito.

Em março de 1918 a Rússia se retirou da $1^{\text {a }}$ GM, sendo um alívio para toda a nação. Porém, mesmo com a derrubada do governo provisório e do czar pelos sovietes, a revolução ainda não estava consolidada porque já em 1917 começou uma contrarrevolução, o exército branco que foi apoiado por 10 países (França, Inglaterra, Japão, Canadá, Estados Unidos da América, Sérvia, Finlândia, Romênia, Turquia e Grécia) tentou retornar ao poder e lutou contra o exército vermelho que foi criado por Trotsky, mas os bolcheviques venceram os combates em 1921 e a guerra civil foi cessada (MARQUES, 2017). Em 1922 foi formada a União das Repúblicas Socialistas Soviéticas (URSS), constituída por 15 repúblicas socialistas, ou seja, 14 países se juntaram a Rússia e formaram uma nação comunista.

Em 1924 aconteceu a morte de Lênin e a URSS perdeu o seu chefe de estado. Em homenagem ao líder da revolução russa a cidade de Petrogrado passou a se chamar Leningrado. Após esse ocorrido, começou uma intensa disputa pelo poder da URSS entre Trotsky e Stalin, ocorrendo um golpe de estado por Stalin que implantou uma ditadura e governou de 1924 até sua morte em 1953 (LIDA, 2017) - veja 
isso em https://www.youtube.com/watch?v=I mUb8sP04Q. Infelizmente o regime comunista não continuou com Stalin, essa ditadura matou várias pessoas. Inclusive Trotsky teve que deixar a URSS em 1929 e fugiu pela Europa, vindo conseguir asilo político no México e foi morto por um espião stalinista com um golpe de picareta na cabeça em 1940. Os opositores políticos de Stalin que não foram mortos eram presos na Sibéria (no gulag) para fazerem trabalho forçado.

Um dos poucos benefícios de Stalin no comando da URSS aconteceu na $2^{a}$ Guerra Mundial $\left(2^{a}\right.$ GM foi de 1939 a 1945). Isso ocorreu na batalha de Stalingrado, o exército vermelho dos soviéticos (criado por Trotsky) derrotou os alemães nos combates durante a invasão nazista na URSS (VASCONCELOS, 2012). Após o sucesso soviético nessa batalha os aliados praticamente obtiveram vitória na $2^{\text {a }}$ GM frente aos países do eixo (Alemanha, Itália e Japão). Na batalha de Berlin a URSS conquistou a Alemanha e a guerra praticamente acabou. Terminada a $2^{\mathrm{a}} \mathrm{GM}$ vários países da Europa centro oriental (Bulgária, Thecoslováquia, Hungria, Polônia, Romênia, Iugoslávia, Alemanha Oriental, Albânia etc) adotaram o regime político da URSS (MARTINS, 2002).

Após a morte de Stalin em 1953, sucederam diversos presidentes na URSS e o regime político continuou por um sistema ditatorial, tendo como líder da nação Nikita Kruschev (1953 a 1964) depois Leonid Brejnev (1964 a 1982) em seguida Iúri Andropov (1982 a 1984) em penúltimo Konstantin Chernenko (1984 a 1985). O último presidente da URSS foi Mikhail Gorbatchev (1985 a 1991) tentou modernizar a política da URSS através da Perestroika (abertura da economia soviética) e da Glasnost (possibilidade de discutir os problemas políticos), mas essa iniciativa fracassou e a URSS entrou em colapso econômico (BARRETO, 2017). Esse declínio econômico da URSS ocasionou no povo soviético um aumento da pobreza que desencadeou elevação do consumo de drogas e crescimento do alcoolismo, também os níveis de prostituição dispararam (GAIDZINSKI, 2017) - veja isso em https://www.youtube.com/watch?v=Y4p6MvwpUeo $\quad$ ou em https://www.youtube.com/watch?v=TUhgDrXrBV0. Além disso, o sistema de saúde e de educação da URSS se tornaram precários com a Perestroika e a Glasnost. Outro problema para o povo soviético foi a falta dos produtos básicos de higiene e de alimentação. Aproveitando o tumultuado governo de Gorbatchev, Boris Yeltsin comandou um golpe de estado com apoio do exército e promoveu o fim da URSS (terminou em 25 de dezembro de 1991, a cidade de Leningrado voltou a ser São Petersburgo) para implantar uma política neoliberal do capitalismo na Rússia no qual se tornou presidente (KLEIN, 2001)veja em https://www.youtube.com/watch?v=jk1Ru35IzdA e em https://www.youtube.com/watch?v=RL1CMCnnKTA. No governo de Yeltsin a pobreza aumentou ainda mais na Rússia e o desemprego cresceu em demasia principalmente porque muitas empresas estatais foram privatizadas. A inflação com a política neoliberal de Yeltsin elevou assustadoramente e o custo dos produtos no mercado ficaram muito caros. A falta de perspectiva em relação ao futuro na Rússia resultou em uma elevação da violência, ocasionando maior número de assaltos no país.

O comunismo teve duração de 8 anos (de 1917 a 1924), iniciando na Rússia revolucionária e posteriormente continuou na URSS. Apesar da breve período do comunismo, ele causou um impacto 
positivo no mundo e proporcionou vários benefícios para a sociedade (direito trabalhista, na saúde e na educação, no esporte). Então, sabendo da importância da revolução russa, torna importante o estudo sobre esse tema.

O objetivo da revisão foi de apresentar os benefícios da revolução russa referente ao direito trabalhista, na saúde e na educação, no esporte.

\section{Direito trabalhista}

Até o século XX os trabalhadores do campo e da fábrica costumavam realizar o serviço por mais de 10 horas por baixos salários (POCHMANN, 2018). Isso começou a causar descontentamento, em 21 de abril de 1856 na Austrália o povo resolveu comemorar o dia do trabalho com o intuito de reduzir a jornada de trabalho de mais de 10 horas para 8 horas (LUXEMBURGO, 1894).

No dia $1^{\circ}$ de maio de 1886 os operários estadunidenses de Chicago imitaram os australianos comemorando o dia do trabalho com o intuito de diminuir às 13 horas de serviço para 8 horas (BARBOSA, 2015). Porém, nesses dois países o trabalhador foi reprimido pela polícia para não realizar esse ato (LUXEMBURGO, 1894). Mas mesmo com essa repressão o $1^{\circ}$ de maio passou a ser comemorado pelos trabalhadores do mundo. Uma das primeiras cidades a reduzir a jornada de trabalho para 8 horas foi a cidade de Chicago em 1890.

A jornada de trabalho de 8 horas é mais saudável para o empregado porque o trabalhador tem menos chance de adoecer por causa do serviço (ROSSO, 2013). Sabendo disso e preocupado com a classe trabalhadora, o líder da Rússia revolucionária estabeleceu jornada de trabalho de 8 horas (MARCONSIN, 2014). No capítulo 10 da Constituição da URSS a jornada de trabalho continuou a ser de 8 horas, mas outros quesitos foram aperfeiçoados como 6 a 7 horas de trabalho se o serviço for difícil e 4 horas de trabalho se o serviço for extremamente difícil (ABRÁMOVA, 2017). Na Rússia comunista foi determinado que o empregador é responsável pelo acidente de trabalho do funcionário, tendo que custear o ocorrido (MARCONSIN, 2014) e em caso de acidente que ocasione deficiência física do trabalhador a empresa era responsável pelo seguro deficiente (ROSENTHAL, 2018). Outra conquista foi a obrigatoriedade da empresa de fornecer equipamentos segurança para uso do empregado durante o serviço (MARQUES JUNIOR, 2017).

Em 1905 Alemanha, Áustria-Hungria, Noruega e Dinamarca foram os primeiros países a fornecer férias remuneradas para os operários das fábricas (NUNES, 2017). Porém, na Rússia comunista as férias remuneradas estenderam a todas as profissões e foi estabelecido para as empresas de fornecer assistência de saúde ao trabalhador (ABRÁMOVA, 2017). Ainda foi determinado que um determinado tempo de serviço o trabalhador tinha direito a aposentadoria (PIMENTA, 2017).

Os primeiros direitos trabalhistas concedidos às mulheres trabalhadoras ocorreram na Inglaterra em 1842 (proibiu o trabalho em locais insalubres) e em 1844 (não permitiu longa jornada de trabalho) (SIQUEIRA, 2017). A primeira Constituição da República Soviética de julho de 1918 concedeu diversos 
benefícios para as mulheres como salário igual ao do homem, licença maternidade remunerada e direito de poder a concorrer a cargos públicos e outros (BENGOECHEA; SANTOS, 2017).

\section{Saúde e educação}

O sistema de saúde da Rússia era gratuito para todas as idades, sendo importante para o povo que não tinha acesso na época do czar (GOMES; SOUZA; MARTINS, 2017). A Rússia foi o primeiro país a legalizar o aborto no dia 10 de novembro de 1920 (BARROS, 2017). Em 1936 sob o comando de Stalin o aborto voltou a ser proibido. Outra iniciativa dos bolcheviques, eles forneceram gratuitamente creche e escola para crianças menores nos locais de trabalho das mães com o objetivo de evitar o abandono do serviço das mulheres (BENGOECHEA; SANTOS, 2017).

Poucos dias após a revolução de outubro de 1917 foi criado o Comissão Nacional de Educação (SAVIANI, 2011) que objetivava melhorar o ensino porque muitas pessoas eram analfabetas (ABREU, 2015). A partir de 1920 os bolcheviques formaram a Comissão Especial da Erradicação do Analfabetismo para toda Rússia com ensino gratuito (SAHNO, 2017) - ver figura 1.

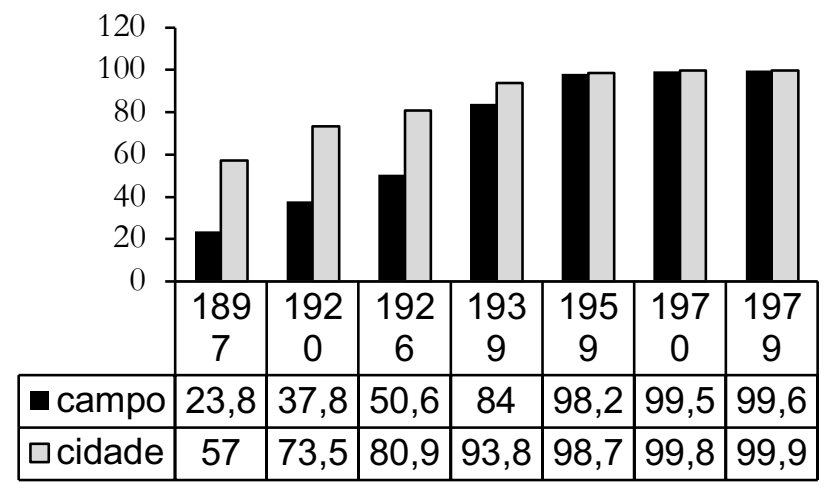

Figura 1. Percentual de pessoas alfabetizadas na Rússia e na URSS.

O ensino gratuito de qualidade ia da creche até a universidade com o intuito de ocasionar um avanço no país na ciência e na tecnologia (OLIVEIRA, 2018) e também era necessário investir em pesquisa para desenvolver equipamentos bélicos de excelência para proteger o imenso território do país (BOLAÑOS, 2018). Segundo o professor de física Dmitri Gitman, os alunos universitários podiam adquirir livros por preços simbólicos e o incentivo para se tornar um pesquisador era grande pelo fato dos cientistas receberem altos salários - veja em https://www.youtube.com/watch?v=uVYSvzBqjo0 ou em https://www.youtube.com/watch?v=mufqxVWtGUA.

Em 1917 foi estabelecido para toda escola a prática da atividade física e do esporte porque era importante para o povo russo (CÓRDOBA; CONTRERAS, 2015). Em 1918 na Rússia foi criado o Instituto Central do Estado de Educação Física de Moscou para formar professores de educação física com intuito de ensinar esporte e atividade física para essa nação (PLATONOV, 2004). Um instituto similar a esse foi implantado em 1930 na Ucrânia. Visando a massificação do conhecimento científico, em 1925 foi elaborada a revista Teoria e Prática da Cultura Física que informava sobre o esporte performance 
(PLATONOV, 2004). Em 1932 em Moscou, foi inaugurada a editora Cultura Física e Esporte para informar cientificamente os treinadores através de livros e revistas sobre as descobertas soviéticas. Portanto, essa área do conhecimento era muito importante para o soviético.

\section{Esporte}

Em 1917 a 1923 na Rússia, o esporte e a atividade física eram grátis a sua prática porque essa tarefa proporcionava melhora da saúde e do condicionamento físico, mas a maior atenção era dada para o preparo militar com o intuito de fortalecer o exército vermelho (IBARROLA, 2018). Por esse motivo Lênin solicitou aos militares em 1923 para desenvolverem uma arte marcial útil para o exército russo, sendo pesquisadas diferentes maneiras de combate da China, Mongólia e Japão (boxe, savate, judô e kung fu) que resultaram no sambo ou autodefesa sem armas (MELO et al., 2017).

Mas nesse período o esporte competitivo era considerado um passatempo burguês porque visava o lucro e o individualismo da vitória, ideias do capitalismo (TUBINO, 1987). Logo, o esporte de rendimento poderia prejudicar comunismo que estava sendo implantado na Rússia, não sendo estimulada a sua prática. O governo buscou um sistema esportivo que atendesse a classe trabalhadora, sendo introduzido o termo cultura física que abrangia a preparação física e a educação física para o desenvolvimento do homem no aspecto físico, espiritual e ético para a formação do cidadão. Somente nos anos 30 que a URSS começou estimular a prática do esporte competitivo (JESUS, 2010).

Entretanto, mesmo o governo tendo resistência ao esporte performance, em 1917 o russo Kotov desenvolveu uma periodização para estruturar o treino dos esportistas russos (MARQUES JUNIOR, 2017). Após esse momento foram conduzidas sucessivas pesquisas sobre periodização que resultaram em diversos modelos. Portanto, os soviéticos aperfeiçoaram a periodização criada pelos gregos que disputavam os Jogos Olímpicos da antiguidade.

Três dias após a revolução russa, Lênin recomendou nas escolas a prática da ginastica, da natação, dos jogos esportivos e do esqui (LOUIS, 1980). Ao longo dos anos, o atletismo, a natação e a ginástica artística passaram fazer parte da educação física escolar (BOMPA, 2002). O halterofilismo era um esporte de interesse dos soviéticos para preparar um povo forte e formou o bicampeão olímpico (72 e 76) Vassili Alekseiev que foi eleito atleta da década de 70 - ver na figura 2.

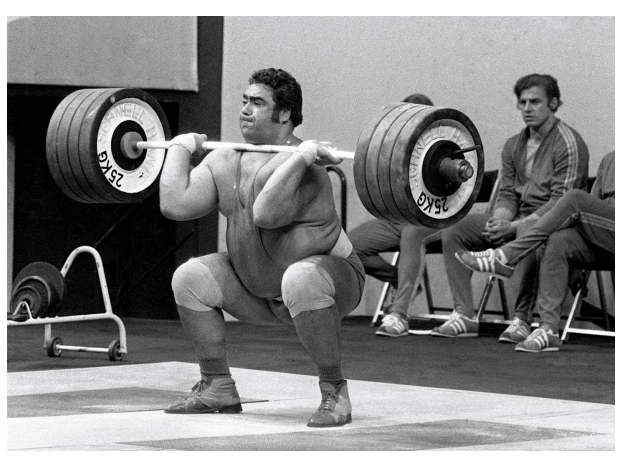

Figura 2. Alekseiev da categoria superpesado. 
O russo Matveev elaborou a periodização tradicional nos anos 40 e 50 através da natação, do atletismo e do halterofilismo. Talvez ele tenha usado a natação e o atletismo porque eram da educação física escolar e o halterofilismo era popular. Esse modelo foi utilizado pela URSS para a Olimpíada de 1952. Em 1965 Matveev apresentou a estatística dos atletas soviéticos com o uso do seu modelo, esse conteúdo formou as bases da ciência do treino esportivo moderno (BARBANTI, 1997). Por esse motivo Matveev é considerado o pai da periodização moderna e do treinamento esportivo - ver na figura 3.
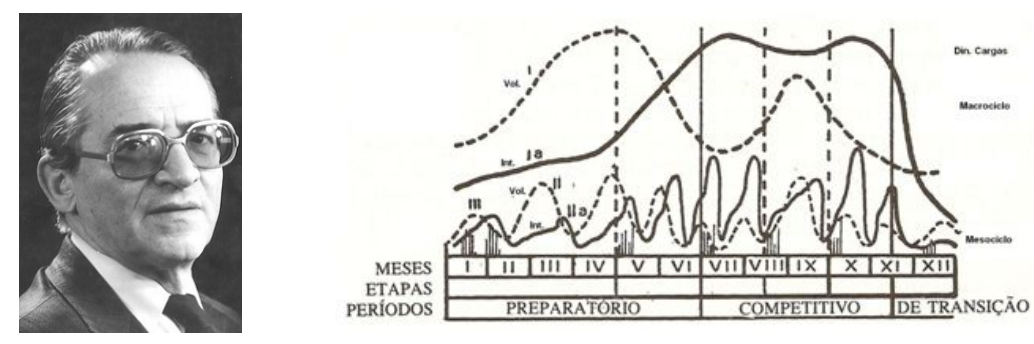

Figura 3. Matveev e o desenho da sua periodização.

O russo Verkhoshanski conduziu vários experimentos nos anos 50 e 60 sobre a força rápida e a força reativa onde desenvolveu baseado na biomecânica a preparação de força especial (PFE) e o método de choque (VERKHOSHANSKI, 1996). A PFE o atleta executa o gesto esportivo com peso de musculação e o método de choque é exercitado no ciclo de alongamento e encurtamento do músculo através do treino de força reativa (TFR) - ver figura 4.

A

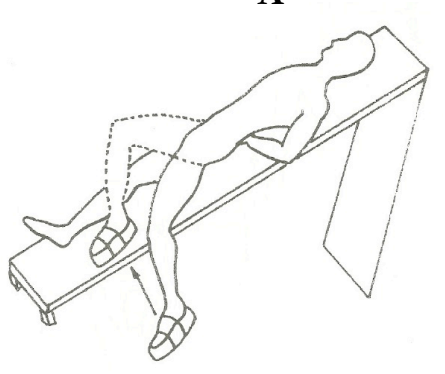

B

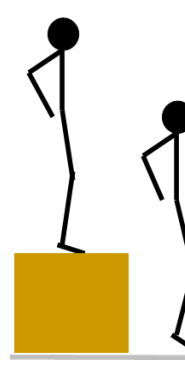

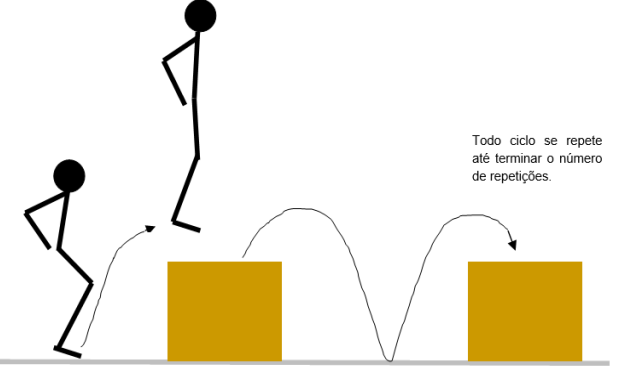

Figura 4. (A) PFE para a corrida e (B) TFR para as pernas.

No fim dos anos 70 e no início dos anos 80 Verkhoshanski elaborou a periodização em bloco para esportes de força rápida, sendo muito utilizado na Olimpíada de 1980 e atualmente - ver figura 5.
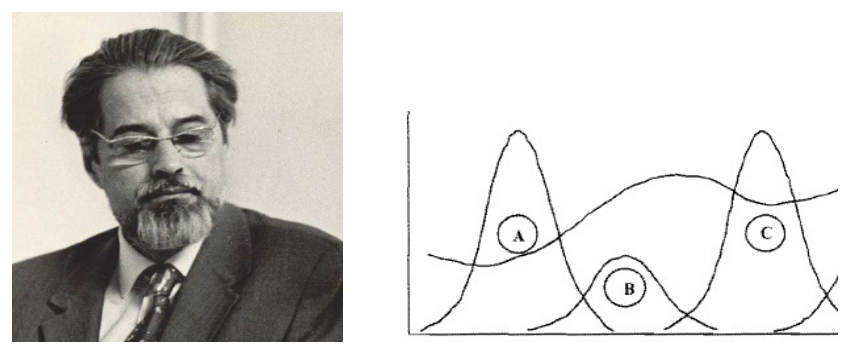
Figura 5. Verkhoshanski e o desenho da sua periodização.

$\mathrm{Na}$ URSS os atletas eram selecionados crianças por testes cineantropométricos com o intuito de direcionar para o melhor esporte. Em 1966 os soviéticos elaboraram a dermatoglifia digital para selecionar talentos esportivos pelas impressões digitais e esse método é utilizado nos dias atuais (MELO; FERNANDES FILHO, 2004).

O voleibol foi introduzido em 1920 na Rússia e sua prática foi estimulada porque ele reproduz as ideias do comunismo, todos se ajudando para atingir um único objetivo (MARQUES JUNIOR, 2012). Por esse motivo o voleibol dos países socialistas tinham melhores desempenhos nas disputas e após o fim da URSS várias nações deixaram de ser socialistas e declinaram nesse esporte - ver figura 6.

\section{Mundial de $\mathbf{4 9}$ a 90 (URSS existe)}

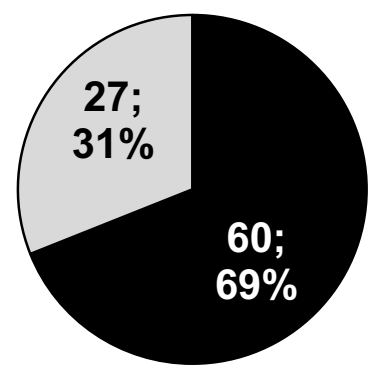

\section{Jogos Olímpicos de 64 a 88 (URSS existe)}

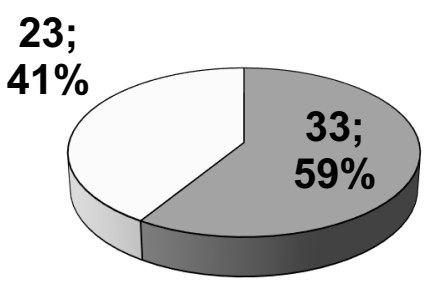

\section{Mundial de 94 a 18 (fim da URSS)}

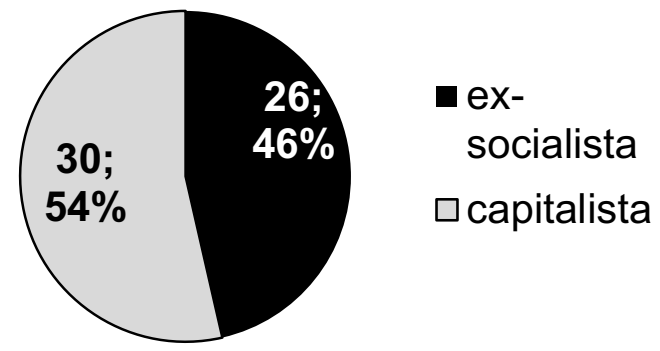

Jogos Olímpicos de 92 a 18 (fim da URSS)
- socialista

$\square$ capitalista
22;

$41 \%$

口ex-

socialista

$\square$ capitalista

Figura 6. $1^{\circ}$ ao $4^{\circ}$ lugar do voleibol de ambos os sexos coletado na FIVB (http://www.fivb.com/) sobre o mundial e a olimpíada - total e percentual.

\section{Considerações finais}

A revolução russa de 1917 causou um impacto positivo para a humanidade e diversos desses benefícios são utilizados no mundo capitalista. Em conclusão, o socialismo é o meio da sociedade se tornar mais igualitária e com melhor qualidade de vida. 


\section{Referências}

ABRÁMOVA, Marianna. Los derechos humanos en el sistema jurídico de Rusia. Boletín Mexicano de Derecho, v. 25, n. 145, p. 531-554, 2017.

ABREU, Malila. O legado educacional da transição Russa. Revista Histedbr, n. 65, p. 328-343, 2015.

ALBUQUERQUE, Jefferson. O impacto da revolução russa no Brasil (1917-1920). Dissertação de Mestrado, UFCG, Mestrado em História, 2018.

BARBANTI, Valdir. Teoria e prática do treinamento esportivo. $2^{a}$ edição. São Paulo: Blücher, 1997.

BARBOSA, Adriana. Direitos trabalhistas da mulher. Monografia de Graduação, UEPB, Bacharel em Direito, 2015.

BARRETO, Gustavo. Nação vermelha. In. DAMASCENO, Diana; BITTENCOURT, Luís; FITTIPALDI, Maristela (Org.). Revolução russa e imprensa no Brasil. Rio de Janeiro: Ventura, 2017. p. 69-74.

BARROS, Anelise. A família na URSS de 1920 a 1936. Veredas da História, v. 10, n. 1, p. 276-288, 2017.

BARTZ, Frederico. O horizonte vermelho: o impacto da revolução russa no movimento operário do Rio Grande do Sul, 1917-1920. Dissertação de Mestrado, UFRGS, Mestrado em História, 2008.

BENGOECHEA, Soledad; SANTOS, María. Las mujeres la revolución rusa. Viento Sur, n. 150, p. 18 25, 2017.

BOLAÑOS, Ronald. El desarrollo científico y tecnológico en la Unión Soviética. Revista Estudios, n. 36, p. 1-45, 2018.

BOMPA, Tudor. Periodização. $4^{a}$ edição. São Paulo: Phorte, 2002.

CÓRDOBA, Eugenia; CONTRERAS, Omar. Historia de la psicología del deporte. Apunts de Psicología, v. 33, n. 1, p. 39-46, 2015.

DOS SANTOS, Emmanuel. Aqueles perigosos radicais socialistas. História e Cultura, v. 6, n. 1, p. 3460, 2017.

GAIDZINSKI, Caio. Abrem-se as cortinas: o fim da União Soviética. Monografia de Graduação, UNESC, História, 2017.

GOMES, Marco; SOUZA, Marilsa; MARTINS, Márcio. Apontamento sobre o legado da revolução russa de 1917. Germinal, v. 9, n. 3, p. 262-275, 2017.

GONZÁLEZ, Horácio. A revolução russa. $3^{a}$ ed. São Paulo: Moderna, 1986.

IBARROLA, David. Reflexiones acerca del deporte soviético. Lúdicamente, v. 7, n. 14, p. 1-17, 2018.

JESUS, Diego. Foices e martelos no olimpo. Recorde, v. 3, n. 2, p. 1-28, 2010.

KLEIN, Naomi. The shock doctrine. New York: Metropolitan Books, 2001.

LIDA, Miranda. Cultura, sociedade, vida cotidiana y política durante el estalinismo. Revista de Historia Social y de las Mentalidades, v. 21, n. 2, p. 61-77, 2017.

LOUIS, Victor. Sport in the Soviet Union. $2^{\text {nd }}$ edition. Oxford: Pergamon, 1980.

LUXEMBURGO, Rosa. Quais são as origens do dia dos trabalhadores. Sprawa Robotnicza, v. -, n. -, p. -, 1894. Disponível em: https://www.marxists.org/portugues/luxemburgo/1894/02/dia.htm Acesso em: 16 de abril de 2019.

MACAMBIRA, Dalton. O centenário da revolução russa. Revista do Departamento de História e do Programa de Pós-Graduação em História do Brasil da UFPL, v. 6, n. 1, p. 23-44, 2017.

MARCONSIN, Cleier. Ditadura militar no Brasil. Revista em Pauta, v. 12, n. 33, p. 45-63, 2014.

MARQUES JUNIOR, Nelson. A revolução russa e o desenvolvimento da periodização esportiva na União Soviética. Revista Inclusiones, v. 4, n. especial, p. 110-127, 2017. 
MARQUES JUNIOR, Nelson. História do voleibol. Lecturas: Educación Física y Deporte, v. 17, n. 169, p. 1-13, 2012.

MARQUES, Rosa. A economia russa no momento da revolução. Revista Socialismo e Liberdade, v. -, n. 20, p. 34-39, 2017.

MARTINS, Angela. Autonomia e educação: a trajetória de um conceito. Cadernos de Pesquisa, v. -, n. 115, p. 207-232, 2002.

MAT'TOS, Marcelo. Os sovietes, peças decisivas da revolução: conselho de trabalhadores foram órgãos de poder criados em 1905 e recriados em 1917. Revista Socialismo e Liberdade, v. -, n. 20, p. 34-39, 2017.

MELO, Márcio; SILVA, Cristiane; PEREIRA, Rayssa; VALLE, Sheila. Aplicabilidade da qualidade física força no sambo. Revista Saúde Física e Mental, v. 5, n. 2, p. 70-81, 2017.

MELO, Mariana; FERNANDES FILHO, José. Perfil dermatoglífico de judocas brasileiros. Fitness and Performance Journal, v. 3, n. 6, p. 340-349, 2004.

MUSSI, Daniela. O incômodo de Kollontai. Revista Socialismo e Liberdade, v. -, n. 20, p. 55-60, 2017.

NOGUEIRA, Flavio. A busca pela modernização: uma análise comparativa entre Rússia Imperial (1861-1914) e a Rússia Soviética (1921-1939). Dissertação de Mestrado, UFRJ, Mestrado em Economia, 2018.

NUNES, Guilherme. Ócio e lazer na regulamentação das férias operárias. Anuário del Instituto de História Argentina, v. 17, n. 1, p. 1-18, 2017.

OLIVEIRA, Agamenon. C\&T na Rússia. $\mathbf{1 6}^{\circ}$ Seminário Nacional de História de Ciência e da Tecnologia, UFCG/UEPB, 15 a 18 de outubro, 2018.

PIMENTA, Rui. 100 anos da revolução russa. PCO. Parte III. Disponível em: Acesso em: https://www.youtube.com/watch?v=PZSA3r6imq8 16 de abril de 2019.

PIMENTA, Rui. 95 anos da revolução russa. PCO. Parte I. Disponível em: Acesso em: https://www.youtube.com/watch?v=MZDtmWSuXV8 16 de abril de 2019.

PLATONOV, Vladimir. Teoria geral do treinamento desportivo olímpico. Porto Alegre: Artmed, 2004.

POCHMANN, Marcio. Desestabilização do trabalho. Saúde Debate, v. 42, n. especial, p. 67-77, 2018.

ROSENTHAL, Keith. A revolução russa e os deficientes. Revista Outubro, n. 30, p. 143-171, 2017.

ROSSO, Sadi. Jornadas excessivas de trabalho. Revista Paranaense de Desenvolvimento, v. 34, n. 124, p. 73-91, 2013.

SAHNO, Elena. A tentativa de construir a igualdade de gênero na Rússia 1917-1937. Dissertação de Mestrado, Ciências Sociais, 2017.

SANTOS, Alane; SANTOS, Andréia; COSTA, Gecássia. Uma abordagem geopolítica sobre os aspectos sociais e econômicos da revolução russa. Anais do $1^{\circ}$ Congresso Brasileiro de Geografia Política e Gestão do Território, Rio de Janeiro, p. 19-26, 2014.

SANTOS, Rosenverck. A revolução que abalou o mundo. Revista de Políticas Públicas, v. 22, n. 2, p. 657-674, 2018.

SAVIANI, Nereide. Concepção socialista de educação. Revista Histedbr, n. especial, p. 28-37, 2011.

SECCO, Lincoln. O centenário da revolução russa. Estudos Avançados, v. 31, n. 91, p. 81-95, 2017. SIQUEIRA, Dirceu. Os direitos da mulher. Revista Direito em Debate, v. 26, n. 48, p. 287-325, 2017.

TUBINO, Manoel. Teoria geral do esporte. São Paulo: Ibrasa, 1987.

VASCONCELOS, André. A produção historiográfica sobre a batalha de Stalingrado. In.

VASCONCELOS, André; LENZ, Sylvia (Org.). Segunda guerra e pós-1945: outras abordagens.

Londrina: UEL; 2012. p. 57-79.

VERKHOSHANSKI, Yuri. Força: treinamento da potência muscular. Londrina: CID, 1996. 


\section{Notas:}

1 Membro Científico da Revista Observatorio del Deporte, Universidade de Los Lagos, Santiago do Chile. ORCID: Email: kautzner123456789junior@gmail.com

Recebido em: 21/04/2019

Aprovado em: 27/05/2019 